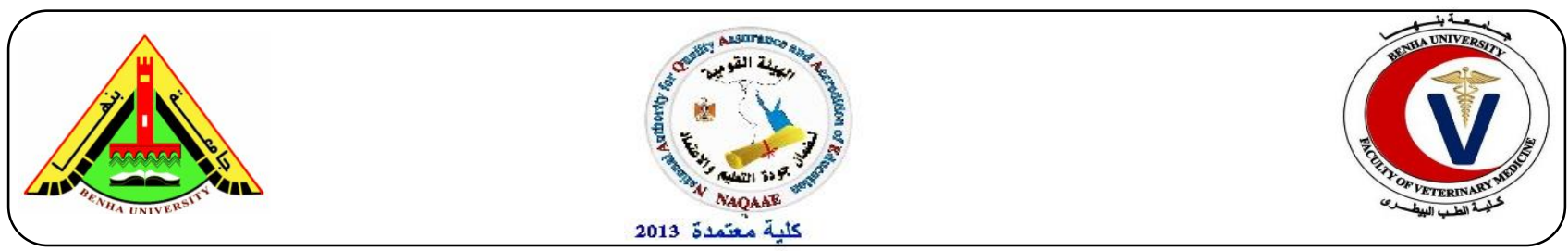

\title{
Influence of pesticides pollution on mitochondrial 12S rRNA gene in cultured Mugil capito from different regions at Kafr El-Shiekh governorate, Egypt
}

Afaf D. Abd El Megid', Mohammad E. Abd Al Fatah', Amel M. El Asely ${ }^{* 2}$, Yakout A. El Senosi ${ }^{1}$, Mahmoud M. A. Moustafa ${ }^{3}$

${ }^{1}$ Department of Biochemistry. Faculty of Veterinary Medicine, Benha University.

${ }^{2}$ Department of of Fish Diseases and Management. Faculty of Veterinary Medicine, Benha University.

${ }^{3}$ Department of of Genetics and Genetic Engineering. Faculty of Veterinary Medicine, Benha University.

\section{A B S T R A C T}

The aim of this study was to evaluate the impacts of pesticides pollution on the sequence of mitochondrial $12 \mathrm{~S}$ rRNA in liver tissues of Mugil capito that obtained from three different regions at Kafr El Sheikh Governorate, Egypt. The results revealed ten SNPs between three sequences of different regions after alignment of these sequences submitted under accession numbers (MF817450.1), (MG210582.1) and (MG210583.1) with sequence with accession number (KU681005.1). Overall, the pesticides pollution has able to happen mutation in the mitochondrial gene.

Keywords: Mugil capito, pesticides, SNPs, 12S rRNA gene sequence.

(http://www.bvmj.bu.edu.eg)

(BVMJ-34(1): 300-304, 2018)

\section{INTRODUCTION}

Recently, there are found that human health might be exposed to hazards from fish consumption due to persistent organic pollutant residues in fish tissues like pesticides (Greco et al., 2010). These pesticides are utilized in agricultural applications and finally diffused into natural water affecting aquatic living. Hence, fish was a good biomarker for aquatic environment pollution with pesticides (Lakra and Nagpure, 2009).

Nowadays, with advanced in biological science field, some studies have focused on determining the side effect of pesticides residues on gene level. There had been detected that it had able to interact with genetic material causing either inactivation or stimulation for nucleic acid replication (Farid and El-Sayed, 2015). Therefore, gene expression can play a crucial role to know the state of fish in the surrounding environment as well as early detection for any changes in the expression of some key genes (Schulte, 2001; Steiner and Anderson, 2000).

Mitochondrial 12S rRNA has proven to be a useful molecular marker for better conservation and management of the endangered species (Siddappa et al., 2013). The rRNA plays a primarily role in protein synthesis. It is, therefore, of particular importance that the structure is taken into account when rRNA genes are aligned, especially when the alignments are intended for phylogenetic analyses (Wang and Lee, 
2002). In order to quantify the extent of compensatory mutations that occurs within 12S rRNA sequences and to discuss the phylogenetic implication of the degree of constraint on compensatory mutations as well as, the nucleotide composition and the patterns of nucleotide substitutions.

Therefore, these changes are very important tool for diagnosis of chemical pollution and pesticides in fish. The aim of this study was to assess the impact of pesticides pollution on mitochondrial 12S rRNA gene sequence in cultured Mugil capito.

\section{Materials and methods}

\section{Fish sampling}

Total number of 150 Mugil capito was collected from the study regions (Al-Hamol, Al Riad and Sidi Salem) fish farms. Liver and dorsal musculature were excised, packed and kept at $-80^{\circ} \mathrm{C}$.

\section{RNA extraction}

Total RNA was extracted from muscle and liver tissues of Mugil capito using TRIzol method according to manufacturer's instructions (Chomczynski, 1993). The quantity of RNA was evaluated by using Nano-drop spectrophotometer and purity by $\mathrm{OD}_{260} / \mathrm{OD}_{280} \mathrm{~nm}$ absorption ratio 1.8:2.0. The obtained total RNA was treated with DNase to remove any contamination with genomic DNA.

\section{PCR reaction and program}

The isolated cDNA were amplified using script RT-PCR two-step kit following the manufacturer protocol (Jena Bioscience, Germany). The used primers obtained using primer3 tool http://primer3.ut.ee/cgibin/primer3/. PCR amplification was carried out by SensoQuest (Labcycler, Germany) using a $50 \mu \mathrm{l}$ of polymerase chain reaction mixture contained: $2 \mu \mathrm{l}$ of cDNA used as template separately, $5 \mu \mathrm{l}$ of $10 \mathrm{x}$ Hot Start Buffer complete, $1 \mu 1$ of dNTP Mix, $0.25 \mu l$ of
Hot Start Pol, $1 \mu 1$ of forward primer $(0.1-0.5$ $\mu \mathrm{M}), 1 \mu \mathrm{l}$ of reverse primer $(0.1-0.5 \mu \mathrm{M})$ and $39.75 \mu 1$ of RNase free Water. The final reaction mixture was placed in a thermal cycler and the PCR program was carried out by initial denaturation at $94{ }^{\circ} \mathrm{C}$ for $2 \mathrm{~min}$ followed by 40 cycles of $94{ }^{\circ} \mathrm{C}$ for $30 \mathrm{sec}$ for DNA denaturation, annealing temperatures as seen in (Table 1) for $30 \mathrm{sec}$, extension at 72 ${ }^{\circ} \mathrm{C}$ for $1 \mathrm{~min}$ and final extension at $72{ }^{\circ} \mathrm{C}$ for $10 \mathrm{~min}$ then were held at $4{ }^{\circ} \mathrm{C}$. Amplified PCR product was analyzed by electrophoresis in $2 \%$ agarose gel stained with Ethidium bromide using 50 bp DNA ladder (Thermo Scientific, USA), then visualized under UV Trans-illuminator.

\section{Cloning and Gene sequencing}

The purified PCR fragment, almost 250bp, was ligated in pGEM®-T Easy Vector Systems (Promega, Germany) according to the manufactures. The competent cells were prepared and transformed according to (Inoue et al., 1990). The white colonies were picked up from LB/Amp/Xgal plates and inoculated on LB/Amp broth media (Sigma-Aldrich, Germany). Then it incubated overnight at $33^{\circ} \mathrm{C}$ for stabilizing the plasmid inside the transformed cells with shaking. The plasmid was isolated according to alkaline method (Birnboim and Doly, 1979). The purified plasmids were analysed by electrophoresis in $1.5 \%$ agarose gel using 50bp DNA Ladder (Thermo Scientific, USA) to confirm the recombinant plasmids. The recombinant plasmids were sent to Macrogen Company (South Korea) for sequencing by ABI 3730XL DNA sequencer (Applied Biosystem, USA).

\section{Phylogenetic analysis}

The obtained sequence for $12 \mathrm{~S}$ rRNA was analyzed with VecScreen tool for vector contamination

(http://www.ncbi.nlm.nih.gov/tools/vecscreen

). The obtained sequence from mitochondrion of Mugil capito was registered 
at NCBI database under accession numbers: MF817450.1, MG210582.1 and MG210583.1 (http://www.ncbi.nlm.nih.gov).

\section{RESULTS}

\section{Identification of 12S rRNA SNPS}

This study revealed effect of pesticides pollution on mitochondrial 12S rRNA gene in Mugil capito that obtain from three different regions within kafr elshiekh government. After sending this gene for sequencing, the results elucidated presence variations among the three different sequences. These sequences were submitted into genebank with accession numbers (MF817450.1) (MG210582.1) (MG210583.1). They aligned to highly similar sequence on genebank with accession number (KU681005.1) reported that there were ten single nucleotide polymorphisms (SNPs). Analysis of those sequences revealed SNPs C29G, G34T, A41T, G57T, A65C, G66C, G79A, C82G, G206T, T220C, and A226G as shown as in Fig

Table 1: The used primers sequences in the current study.

\begin{tabular}{l|l|l|l|l}
\hline $\begin{array}{l}\text { Gene of } \\
\text { interest }\end{array}$ & $\begin{array}{l}\text { Primer sequences } \\
\left(5^{\prime}-3^{\prime}\right)\end{array}$ & $\begin{array}{l}\text { Ta } \\
\left({ }^{0} \mathrm{C}\right)\end{array}$ & $\begin{array}{l}\text { amplification } \\
\text { size (bp) }\end{array}$ & Reference \\
\hline 12S rRNA & $\begin{array}{l}\text { F: CCCACTATGCTCAGCCCTAA } \\
\text { R: CCTGGCGTTTTGGGTCATAC }\end{array}$ & 53 & 250 & $\begin{array}{l}\text { Current } \\
\text { study }\end{array}$ \\
\hline
\end{tabular}

Fig.1. Single nucleotide polymorphism (SNP) image of Mugil capito in different study regions (Al Hamol, Al Riad and Sidi-Salem) with accession number (MF817450.1) (MG210582.1) (MG210583.1) respectively current study produced by Jalview, version 2.10.1 software. 


\section{DISCUSSION}

The present study is an extension to a previous work of Abd El Megid et al., (2018) (under publishing) where the authors did survey on pesticide residue in the studied areas (Al Hamol, Al Riad and Sidi-Salem) for the fish farm water and tissue levels of cultured Mugil capito in the same fish farms belonging to the study areas. The obtained results revealed that Delta-BHC compound was the dominant organochlorine with concentration ranging from 150 to $450 \mathrm{ng} / \mathrm{L}$. in addition to other pyrethroids residues were detected in the ponds water. It was also found that the highest pesticides residue was detected at Al Hamol and Al Riad fish farms and the lowest at Sidi-Salem fish farms. But fortunately; the pesticides residues in fish tissues were below the permissible limits.

Mitochondrial genome is extremely necessary for a life of almost eukaryotic that encoded into 13 proteins, two ribosomal rRNAs and 22 tRNAs that are required for mitochondria protein synthesis (Yang et al., 2014). The results of the nucleotide sequence organization alignment are similar to fish species. In consistence, we have a tendency to found high similarity (95\% identity) in nucleotide sequences of $12 \mathrm{~S}$ rRNA between Mugil capito in current study with that submitted under accession number (KU681005.1). To our data, this can be the primary study to spot ten loci of mitochondrial $12 \mathrm{~S}$ rRNA in Mugil capito in Egypt. The sequences of those loci were submitted into GenBank databases with accession number (MF817450.1), (MG210582.1) and (MG210583.1). Analysis of those sequences revealed SNPs C29G, G34T, A41T, G57T, A65C, G66C, G79A, C82G, G206T, T220C, and A226G. These
SNPs may be attributable to presence of pesticides within the study regions led to some mutations in the sequences of $12 \mathrm{~S}$ rRNA. Surprisingly, variations of SNPs among the various study regions were correlated with the degree of pollution in every region. It could be concluded that, IGF1 and CYP1A genes can be used as sensitive biomarker for assessment contamination in all stages of fish. In addition to the new maker represented by, 12SrRNA sequence analysis.

\section{REFERENCES}

Birnboim, H. C. and Doly, J. 1979. A rapid alkaline extraction procedure for screening recombinant plasmid DNA. Nucleic Acids Res 7, 1513-23.

Chomczynski, P. 1993. A reagent for the single-step simultaneous isolation of RNA, DNA and proteins from cell and tissue samples. Biotechniques 15, 532$4,536-7$.

Farid, S. S. and El-Sayed, D. M. 2015. Pesticides Toxicity in Fish with Particular Reference to Insecticides. Asian Journal of Agriculture and Food Sciences 03.

Greco, L., Serrano, R., Blanes, M. A., Serrano, E. and Capri, E. 2010. Bioaccumulation markers and biochemical responses in European sea bass (Dicentrarchus labrax) raised under different environmental conditions. Ecotox Environ Saf 73, 3845 .

Inoue, H., Nojima, H. and Okayama, H. 1990. High efficiency transformation of Escherichia coli with plasmids. Gene 96, 23-8.

Lakra, W. S. and Nagpure, N. S. 2009. Genotoxicological studies in fishes: A review. Indian J. Anim. Sci. 79, 93-98.

Schulte, P. 2001. Environmental adapations as windows on molecular evolution. 
Comp Biochem Physiol 128B, 597611.

Siddappa, C. M., Saini, M., Das, A., Doreswamy, R., Sharma, A. K. and Gupta, P. K. 2013. Sequence Characterization of Mitochondrial 12S rRNA Gene in Mouse Deer (Moschiola indica) for PCR-RFLP Based Species Identification. Mol Biol Int 2013, 783925.

Steiner, S. and Anderson, N. 2000. Expression profiling in toxicologypotentials and limitations. Toxicol Lett,
$112-113: 467-471$.

Wang, H. Y. and Lee, S. C. 2002. Secondary structure of mitochondrial 12S rRNA among fish and its phylogenetic applications. Mol Biol Evol 19, 138-48.

Yang, L., Tan, Z., Wang, D., Xue, L., Guan, M.-x., Huang, T. and Li, R. 2014. Species identification through mitochondrial rRNA genetic analysis. 4, 4089. 